\title{
Role of magnetic resonance imaging in diagnosis and grading of perianal fistulas
}

\author{
Saurabh S Kakani', Devidas B Dahiphale ${ }^{2}$, Saurabh G Padiya ${ }^{3}$, Vimal G Dugad ${ }^{4}$, \\ Shivaji M Pole ${ }^{5}$, Tanushree A Poddar ${ }^{6}$ \\ 1,3,4,6 Junior Resident, ${ }^{2}$ Professor and Head, ${ }^{5}$ Associate Professor, Department of Radiology, MGM Medical College and \\ Hospital, Aurangabad, Maharashtra, India
}

Background: Fistula-in-ano can be defined as a hollow tract or cavity which is lined by granulation tissue. In case of fistula-in-ano, one end of this fistula opens in the anal canal whereas the other end is located in perianal area. Fistula-in-ano can considerably affect quality of life of an individual because of perianal discharge of blood and pus. Imaging of these fistulas is an important part of management and MR imaging is important in assessing relationship between the fistulous tract and sphincter muscles. Moreover, MR imaging can reliably demonstrate transmural inflammation, secondary tracts/ramifications, and abscesses which cannot be diagnosed on the basis of conventional fistulography. Aims and Objectives: The aim of the study was to evaluate role of MRI in diagnosis and grading of perianal fistulae. Materials and Methods: This was a retrospective observational study, in which 60 patients with fistula-in-ano were included on the basis of a predefined inclusion and exclusion criteria. MR imaging of patients was done by $1.5 \mathrm{~T}$ MRI machine. Before MR imaging normal saline was injected in the fistulous tract from secondary/external opening, that is, opening around perianal area. Three plane images were obtained in all the cases. T1W, T2W, and STIR image sequences were obtained parallel to pelvic diaphragm. Coronal cuts were imaged parallel to anal canal. FAT suppressed T1W and T2W images in all cases. Type and grade of fistula were determined in all the cases. $\mathrm{P}<0.05$ was taken as statistically significant. Results: Out of total 60 patients, there were $46(76.66 \%)$ males and $14(23.33 \%)$ were females with a M:F ratio of $1: 0.30$. The mean age of male and female patients was found to be $41.93 \pm 8.96$ years and $44.04 \pm 7.46$ years, respectively. The most common type of fistula was found to be trans-sphincteric fistula which was seen in $31(51.6 \%)$ cases followed by intersphencteric fistula 22 (36.6\%). Extrasphincteric and suprasphincteric fistulae were relatively uncommon and were seen in $4(6.66 \%)$ and $3(5 \%)$ cases, respectively. MRI was accurate in diagnosis of the tract with position of internal opening and any abscess cavity or secondary tract in 23 patients. Therefore, the diagnostic accuracy of MRI was found to be $95.4 \%$. Conclusion: MRI is an excellent tool in assessment of perianal fistula. It not only helps in precisely locating fistulous tract but also can demonstrate relationship between the fistulous tract and sphincter muscles. Moreover, it can very well demonstrate transmural inflammation, secondary tracts/ramifications, and abscesses which cannot be assessed by conventional fistulograms.

Key words: Magnetic resonance imaging; MR Fistulogram; Secondary tracts/ramifications; Sphincter muscles; Transmural inflammation

\section{INTRODUCTION}

Fistula-in-ano can be defined as a hollow tract or cavity which is lined by granulation tissue. One end of this
Access this article online

Website:

http://nepjol.info/index.php/AJMS DOI: 10.3126/ajms.v12i12.39695 E-ISSN: 2091-0576

P-ISSN: 2467-9100

Copyright (c) 2021 Asian Journal of Medical Sciences

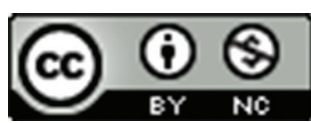

This work is licensed under a Creative Commons Attribution-NonCommercial 4.0 International License. 
multiple secondary openings extending from same primary opening located in anal canal. These fistulae usually arise following perianal abscess. Fistula-in-ano has a tendency to chronicity and significantly affect quality of life. ${ }^{2}$ The major problem associated with fistula in ano include discomfort resulting from continuous drainage from fistula leading to hygienic problems, in some cases this may cause serious complications such as septicemia. ${ }^{3}$

It is crucial to properly assess theses fistula-in-ano because surgical intervention must be aimed at not only eradication of fistulous tract thereby eradication of source of infection but also maintenance of continence which depends on maintenance of anal-sphincter complex. ${ }^{4}$ Thus, pre-operative assessments of fistula-in-ano are one of the crucial components of management. Advanced imaging technique such as MR imaging has become crucial in identifying infected fistulous tracts and abscess that would have been impossible or at least difficult to assess by other conventional imaging methods. ${ }^{5}$

One of the common problems associated with conventional imaging methods such as conventional fistulograms is that while they can demonstrate the fistulous tract excellently, they usually fail to demonstrate the inflammatory process which has reached transmural tissue. ${ }^{6}$ In this regard, MR imaging can be very helpful in knowing the involvement of tissue surrounding fistulous tract. Another limitation of conventional fistulogram is that it cannot demonstrate the relationship between the fistulous tract and sphincter muscles consequently involvement of internal and external anal sphincter as well as levator anti muscle cannot be ascertained, this limitation can be very well taken care of by MR fistulography. ${ }^{7}$

MR fistulography has the distinct advantage of not only depicting the fistulous tract but also it can demonstrate the extent of transmural inflammatory process secondary tracts/ramifications and abscesses. It also can precisely show the relationship between the fistulous tract and sphincter muscles. ${ }^{8}$ Moreover, it can very well image a fistulous tract which is filled with pus and debris (Conventional fistulograms may fail to fill the tract if its blocked by debris). ${ }^{9}$ Perianal fistulas are divided on the basis of relationship of the fistulous tract and the anal sphincter. The two most common classification system used are the Park's classification and the St James university hospital classification. The Park's classification is based on coronal imaging. The other classification and also the most accepted and convenient classification used is the St James university hospital classification. ${ }^{10}$ In this classification, the presence of secondary tract or ramifications and perianal abscesses is also taken into consideration. Classification is based on both axial and coronal imaging. On the basis of Park's classification, the fistulas can be divided into intersphincteric, transsphincteric, suprasphincteric and extrasphincteric depending on the fistulous tract and its relationship with anal sphincters. ${ }^{11}$

We conducted this study to know role of magnetic resonance imaging in diagnosis and grading of perianal fistulas.

\section{Aims and objectives}

The aim of the study was to evaluate role of MRI in diagnosis and grading of perianal fistulae.

\section{MATERIALS AND METHODS}

This was a retrospective observational study, in which 60 patients with fistula-in-ano were included on the basis of a predefined inclusion and exclusion criteria. MR imaging of patients was done in the department of radiology of MGM Medical College and Hospital, Aurangabad using 1.5T MR imaging system.

Patients were explained in details about procedure of imaging as well as need for injection of normal saline in fistulous tract. An informed written consent was obtained from all the patients for injection of normal saline in fistulous tract and those who refused this injection out of fear of pain were excluded from this study. In all patients, it was ascertained that there was no contra-indication to MR imaging such as cardiac pacemakers, metallic implants, or aneurysmal clips. All patients were imaged in supine position. Before MR imaging normal saline was injected in the fistulous tract from secondary opening, that is, opening around perianal area. Three plane images were obtained in all the cases. T1W, T2W, and STIR image sequences were obtained parallel to pelvic diaphragm. Coronal cuts were imaged parallel to anal canal. FAT suppressed $\mathrm{T} 1 \mathrm{~W}$ and $\mathrm{T} 2 \mathrm{~W}$ images in all cases.

MR images were analyzed by senior radiologist for detection of internal as well as external opening, anatomical location and extent of fistulous tract, presence of scars, relationship of fistulous tract to sphincter muscles, and presence of transmural inflammation.

Fistula-in-ano was categorized on the basis of Park's classification. $^{11}$

1. Intersphincteric - In it the fistulous tract lies in the intersphincteric space but does not traverse the external anal sphincter.

2. Transsphincteric - In this the fistulous tract traverses the external anal sphincter and then traverses through the ischioanal/ischiorectal fossa to open subcutaneously. 
3. Suprasphincteric - Here, the fistulous tract traverses above in the intersphincteric space above the puborectalis muscle and then descends through the iliococcygeus muscle into the ischiorectal fossa

4. Extrasphincteric - Here the fistulous tact traverses through the ischiorectal fossa, the levator anti sphincter complex and opens into the rectum in the supra levator region, that is, above the anal sphincter.

Fistula-in-ano was graded on the basis of St Jame's University Hospital classification. ${ }^{10}$

Grade 1- It is the simplest type, that is, simple linear intersphincteric perianal fistulous tract.

Grade - Intersphincteric fistulous tract associated with secondary tract/ramification or abscess cavity.

Grade 3- Transsphincteric fistulous tact without any secondary tract or abscess.

Grade 4- Transsphincteric fistulous tract along with presence of secondary tract or ramification and/or abscess.

Grade 5-Any fistulous tract with supralevator or translavetor extension.

The statistical analysis was done using SSPS 21.0 software and $\mathrm{P}<0.05$ was taken as statistically significant.

\section{Inclusion criteria}

The following criteria were included in the study:

1. Patients diagnosed to be having fistula-in-ano clinically or on the basis of conventional fistulograms.

2. Age of the patients above 18 years.

3. Those who gave consent to be part of study.

\section{Exclusion criteria}

The following criteria were excluded from the study:

1. Age $<18$ years.

2. Those who refused consent to be part of study.

3. Those who refused injection of normal saline in fistulous tract during imaging.

4. Patients having contraindication to MR imaging such as cardiac pacemakers, aneurysmal clips, or metallic implants not compatible with MR imaging.

\section{RESULTS}

A total of 60 patients diagnosed to be having perianal fistula wither clinically or on the basis of conventional fistulography were included in this study. Out of total 60 patients, there were $46(76.66 \%)$ males and $14(23.33 \%)$ were females with a M:F ratio of 1:0.30 (Figure 1).

The most common affected age group was found to be $41-50$ years in males as well as female patients. Out of 60 studied cases $22(36.67 \%)$ males and $8(13.33 \%)$ females belonged to age group of $41-50$ years. The mean age of male and female patients was found to be $41.93 \pm 8.96$ years and $44.04 \pm 7.46$ years, respectively. The mean age of male and female patients was found to be comparable with no statistically significant difference $(\mathrm{P}=0.473)$ (Table 1$)$.

The analysis of patients on the basis of presenting complaint showed that majority of the patients had a presenting complaint of perianal discharge which was seen in $35(58.3 \%)$ patients followed by pain which was seen in $28(46.67 \%)$ cases. $18(30 \%)$ patients reported that their quality of life was significantly hampered due to perianal fistula (Table 2).

Among 60 cases in $49(81.67 \%)$ patients, the cause of fistula in ano could not be established. Tubercular or bacterial infections were found to be the cause of fistula in $3(5 \%)$ cases whereas recurrent abscess formation was found to be the cause of fistula in ano in $8(13.33 \%)$ patients (Figure 2).

The fistulae were classified on the basis of Parks classification. The most common type of fistula was found to be transsphincteric fistula which was seen in $31(51.6 \%)$ cases, followed by intersphincteric fistula (36.6\%). Extrasphincteric and suprasphincteric fistulae were relatively uncommon and were seen in $4(6.66 \%)$ and $3(5 \%)$ cases, respectively (Table 3 ).

Grade 4 (Transsphincteric fistulous tract along with presence of secondary tract or ramification and/or abscess) fistula was found to be the most common type of fistula and was seen in 22 patients followed by Grade I (simple linear intersphincteric perianal fistulous tract) fistula which was seen in $20(33.33 \%)$ patients. Grade 3 fistula (Transsphincteric fistulous tact without any secondary tract or abscess) was seen in $12(20 \%)$ patients. Grade 2 and Grade 4 fistulae were less common and were seen in $4(6.66 \%)$ and $2(3.33 \%)$ cases, respectively (Figure 3).

The most sensitive sequence for detection of perianal fistula was found to be T2W images $(96.6 \%)$, followed by T2FS images (STIR/SPAIR) (95\%). The least sensitive sequence for detection of fistula was T1W images (86.6\%). In this study, we found that the most common location for internal opening was posterior which was seen in approximately $70 \%$ of the patient, followed by anterior $(11.65 \%)$ and right lateral positions $(10 \%)$. Out of the total 60 patients, perianal abscess or collection was found in 12 patients, that is, $20 \%$ of the patient (Figure 4). In 48 patients, no abscess cavity was localized. Secondary tract or ramifications were found in total 19 patients (31.4\%) (Figure 5). No secondary tract or ramification was there 
Table 1: Age distribution of the studied cases

\begin{tabular}{|c|c|c|c|c|}
\hline \multirow[t]{3}{*}{ Age group } & \multicolumn{4}{|c|}{ Number of patients } \\
\hline & \multicolumn{2}{|c|}{ Males } & \multicolumn{2}{|c|}{ Females } \\
\hline & Number of patients & Percentage & Number of patients & Percentage \\
\hline 18-30 years & 2 & 3.33 & 0 & 0.00 \\
\hline $31-40$ years & 14 & 23.33 & 3 & 5.00 \\
\hline $41-50$ years & 22 & 36.67 & 8 & 13.33 \\
\hline $51-60$ years & 5 & 8.33 & 2 & 3.33 \\
\hline Total & 46 & 76.66 & 14 & 23.33 \\
\hline Mean Age & \multicolumn{2}{|c|}{$41.93 \pm 8.96$} & \multicolumn{2}{|c|}{$44.04 \pm 7.46$} \\
\hline
\end{tabular}

\begin{tabular}{lcc}
$\begin{array}{l}\text { Table 2: Presenting complaints of the studied } \\
\text { cases }\end{array}$ & $\begin{array}{c}\text { Number } \\
\text { of patent }\end{array}$ & Percentage \\
\hline Complaint & 35 & 58.33 \\
& 28 & 46.67 \\
Perianal discharge & 18 & 30.00 \\
Pain & 5 & 8.33 \\
Significantly affected quality of life & & \\
Recurrent abscess formation & &
\end{tabular}

Table 3: Classification of fistula on the basis of Parks classification

\begin{tabular}{lcc}
\hline Types & Number of patient & Percentage \\
\hline Intersphincteric & 22 & 36.6 \\
Transsphincteric & 31 & 51.6 \\
Suprasphincteric & 3 & 5 \\
Extrasphincteric & 4 & 6.66 \\
\hline
\end{tabular}

in 41 patients (68.6\%). 24 patients underwent surgery in our institute. MRI was accurate in diagnosis of the tract with position of internal opening and any abscess cavity or secondary tract in 23 patients. Therefore, the diagnostic accuracy of MRI was found to be $95.4 \%$.

\section{DISCUSSION}

A total of 60 patients having perianal fistula were included in this study. Out of total 60 patients, there were $46(76.66 \%)$ males and $14(23.33 \%)$ were females with a M: F ratio of 1:0.30. Abbas et al. conducted a study of patients with anal fistula secondary to cryptoglandular disease and to determine factors that influence postoperative outcome. ${ }^{12}$ In this an overwhelming majority of patients were males $(79.3 \%)$. Similar male preponderance was also reported by the authors such as Stewart et al. ${ }^{13}$ and de Miguel Criado et al. ${ }^{14}$

In our study, mean age of male and female patients was found to be $41.93 \pm 8.96$ years and $44.04 \pm 7.46$ years, respectively. The mean age of male and female patients was found to be comparable with no statistically significant

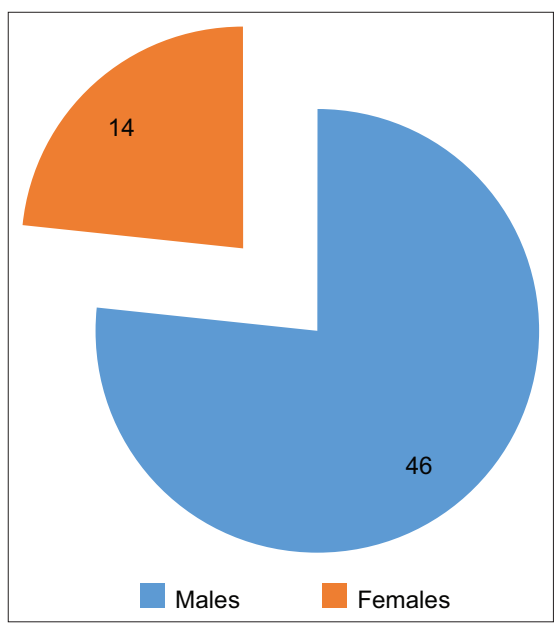

Figure 1: Gender distribution of the studied cases

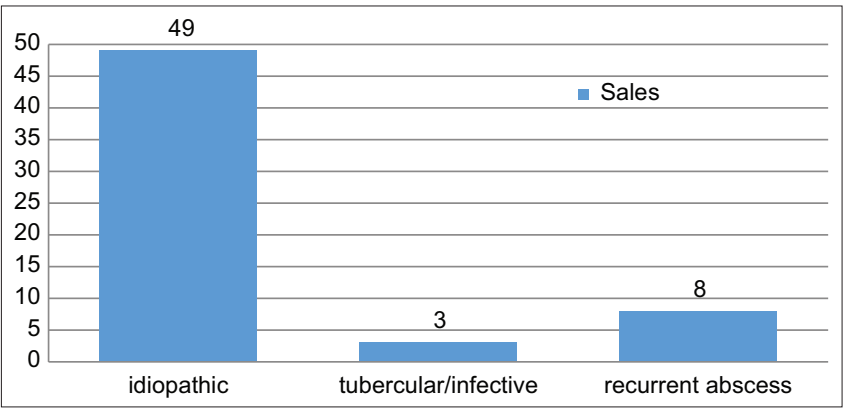

Figure 2: Etiology of perianal fistula in studied cases

difference $(P=0.473)$. Sainio conducted a study of 458 patients to determine incidence and epidemiology of anal fistula during a 10 -year period. The authors found that at the time of diagnosis the mean age of the patients was 38.3 years. The mean age of affected cases in this study was similar to our study. ${ }^{15}$

In our study, perianal discharge (58.3\%) followed by pain $(46.67 \%)$ was common presenting complaints. In $49(81.67 \%)$ patients, the cause of fistula in ano could not be established. Tubercular or bacterial infections were found to be the cause of fistula in $3(5 \%)$ cases 


\begin{tabular}{|c|c|c|c|}
\hline Characterstic & Sequence & Number of patient & Percentage \\
\hline \multirow[t]{3}{*}{ Diagnostic Accuracy of Various MRI Sequences } & TIW images & 52 & 86.6 \\
\hline & $\mathrm{T} 2 \mathrm{~W}$ images & 57 & 95 \\
\hline & T2FS/STIR & 56 & 93.3 \\
\hline \multirow[t]{4}{*}{ Location of Internal Opening } & Anterior & 7 & 11.67 \\
\hline & Posterior & 42 & 70.00 \\
\hline & Right Lateral & 6 & 10.00 \\
\hline & Left Lateral & 5 & 8.33 \\
\hline \multirow{2}{*}{ Presence of Abscess/Collection } & Present & 12 & 20 \\
\hline & Not present & 48 & 80 \\
\hline \multirow[t]{2}{*}{ Secondary Tract or Ramifications } & Present & 19 & 31.6 \\
\hline & Absent & 41 & 68.4 \\
\hline \multirow[t]{2}{*}{ Diagnostic Accuracy of MRI } & Accurate & 23 & 95.8 \\
\hline & Not accurate & 1 & 4.2 \\
\hline
\end{tabular}

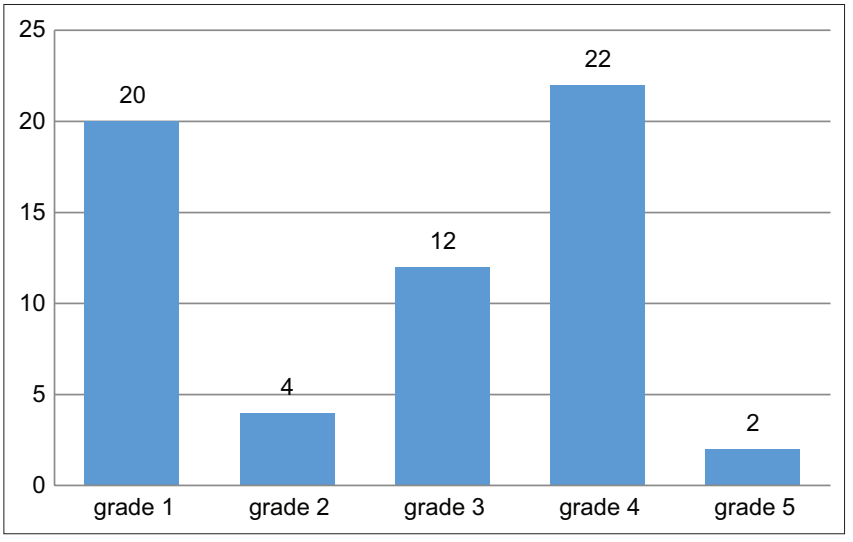

Figure 3: Grading of fistula in studied cases

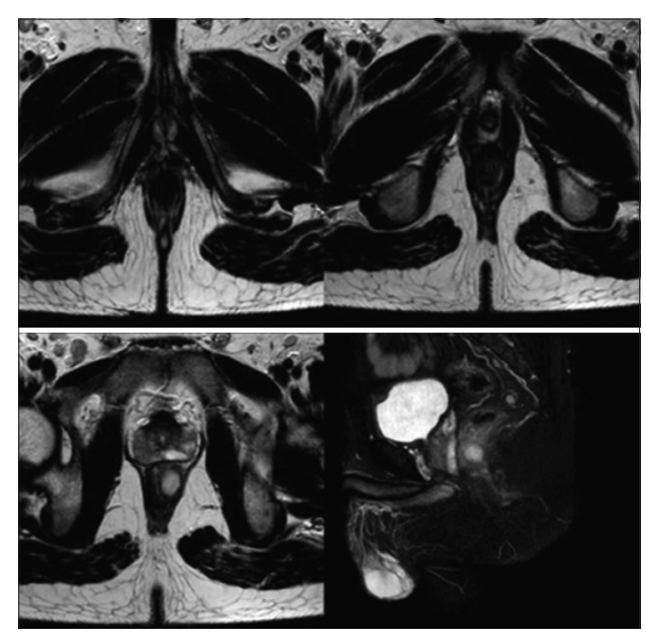

Figure 4: A transsphincteric fistulous tract was seen giving a branching in intersphincteric region with intersphincteric abscess formation

whereas recurrent abscess formation was found to be the cause of fistula in ano in $8(13.33 \%)$ patients. The most common type of fistula was found to be transsphincteric fistula which was seen in $31(51.6 \%)$ cases followed by intersphincteric fistula (36.6\%). Extrasphincteric and suprasphincteric fistulae were

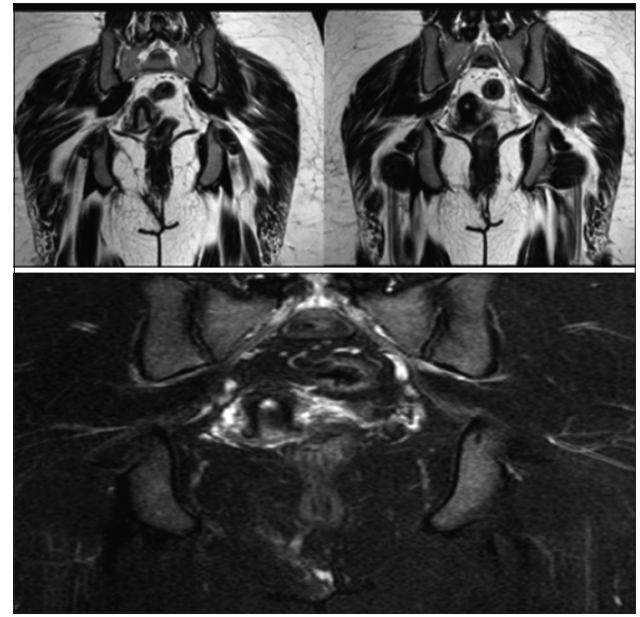

Figure 5: MR fistulography showing a transsphincteric fistulous tract traversing through the right ischioanal region, piercing the external anal sphincter with internal opening into anal canal

relatively uncommon and were seen in 4 (6.66\%) and $3(5 \%)$ cases, respectively. Most of the studies have reported idiopathic type to be the commonest etiological type of perianal fistula. ${ }^{16}$

In our study, Grade 4 fistula was found to be the most common type of fistula and was seen in 22 patients, followed by Grade I fistula which was seen in 20 (33.33\%) patients. Grade 3 fistula was seen in $12(20 \%)$ patients. Grade 2 and Grade 4 fistulae were less common and were seen in $4(6.66 \%)$ and $2(3.33 \%)$ cases, respectively. In a similar study Chaudhari et al. studied MRI images of 35 patients with different types of perianal fistulas. Imaging was performed with multiplanar T1-weighted, T2-weighted, and PDFS sequences. The authors found that out of 35 studied cases 18 (51\%) patients showed Grade 1 (simple linear intersphincteric fistula), 5 (14\%) showed Grade 2 (intersphincteric with abscess or secondary tract), 6 (21\%) showed Grade 3 (transsphincteric), 5 showed Grade 5 (14\%) (transsphincteric with abscess 
or secondary tract in ischiorectal or ischioanal fossa), and none $(0 \%)$ showed Grade 5 (supralevator and translevator). ${ }^{17}$

In our study, the most sensitive sequence for detection of perianal fistula was found to be T2W images (96.6\%), followed by T2FS images (STIR/SPAIR) (95\%). The least sensitive sequence for detection of fistula was T1W images $(86.6 \%)$. In a similar study conducted by Madireddy et al., the authors found that MR fistulography was $97.29 \%$ sensitivity, 66.66\% specific and had 94\% positive predictive value, $50 \%$ negative predictive value, and overall diagnostic accuracy of $95 \%$ in the diagnosis of perianal fistula. ${ }^{18}$ These findings were similar to the findings of our study which found overall diagnostic accuracy of MR imaging for diagnosis of perianal fistula to be $95.8 \%$. Similar diagnostic accuracy was also reported by the authors such as Daabis et al. ${ }^{19}$ and Singh et al. ${ }^{20}$

\section{Limitations of the study}

The limitations of this study included the problem with alignment of MRI images with anal canal axis. Another limitation of study was limited number of patients. Larger studies are required to further substantiate the outcome of this study.

\section{CONCLUSION}

MR imaging of perianal fistula is an excellent tool in assessment of perianal fistula. It is not only useful in diagnosis of fistulae but also can precisely demonstrate the presence of transmural inflammation, secondary tracts/ramifications, and abscesses. It also helps in precisely locating fistulous tract but also can demonstrate relationship between the fistulous tract and sphincter muscles consequently involvement of internal and external anal sphincter as well as levator anti muscle can be reliably ascertained.

\section{ACKNOWLEDGMENT}

The authors would like to acknowledge the guidance given by Dr Prasanna Mishrikotkar (Professor, department of radiology) and assistance provided by Dr Amruta Mandhane (Intern).

\section{REFERENCES}

1. Carr S and Velasco AL. Fistula in ano. In: Stat Pearls. Treasure Island, FL: Stat Pearls Publishing; 2021.
2. Owen HA, Buchanan GN, Schizas A, Cohen R and Williams AB. Quality of life with anal fistula. Ann R Coll Surg Engl. 2016;98(5):334-338.

https://doi.org/10.1308/rcsann.2016.0136

3. Henrichsen $S$ and Christiansen J. Incidence of fistula-in-ano complicating anorectal sepsis: A prospective study. $\mathrm{Br} \mathrm{J}$ Surg. 1986;73(5):371-372.

https://doi.org/10.1002/bjs.1800730515

4. Bokhari S and Lindsey I. Incontinence following sphincter division for treatment of anal fistula. Colorectal Dis. 2010;12(7):e135-e139.

https://doi.org/10.1111/j.1463-1318.2009.01872.x

5. Sharma A, Yadav P, Sahu M and Verma A. Current imaging techniques for evaluation of fistula in ano: A review. Egypt $\mathrm{J}$ Radiol Nucl Med. 2020;51:130.

https://doi.org/10.1186/s43055-020-00252-9

6. Khera PS, Badawi HA and Afifi AH. MRI in perianal fistulae. Indian J Radiol Imaging. 2010;20(1):53-57.

https://doi.org/10.4103/0971-3026.59756

7. Liang $\mathrm{C}$, Lu $\mathrm{Y}$, Zhao B, Du Y, Wang $\mathrm{C}$ and Jiang W. Imaging of anal fistulas: Comparison of computed tomographic fistulography and magnetic resonance imaging. Korean $\mathrm{J}$ Radiol. 2014;15(6):712-723. https://doi.org/10.3348/kjr.2014.15.6.712

8. Bhaya AK and Kumar N. MRI with MR Fistulogram for perianal fistula: A successful combination. Clin Gastrointest Magnetom. 2007;1:56-59.

9. Maier AG, Funovics MA, Kreuzer SH, Herbst F, Wunderlich M, Teleky BK, et al. Evaluation of perianal sepsis: Comparison of anal endosonography and magnetic resonance imaging. J Magn Reson Imaging. 2001;14(3):254-260. https://doi.org/10.1002/jmri.1181

10. Parks AG, Gordon PH and Hardcastle JD. A classification of fistula-in-ano. Br J Surg. 1976;63(1):1-12.

11. Morris J, Spencer JA and Ambrose NS. MR imaging classification of perianal fistulas and its implications for patient management. Radiographics. 2000;20(3):623-635.

https://doi.org/10.1148/radiographics.20.3.g00mc15623

12. Abbas MA, Jackson $\mathrm{CH}$ and Haigh PI. Predictors of outcome for anal fistula surgery. Arch Surg. 2011;146(9):1011-1016.

13. Stewart LK, McGee $J$ and Wilson SR. Transperineal and transvaginal sonography of perianal inflammatory disease. AJR Am J Roentgenol. 2001;177(3):627-632. https://doi.org/10.2214/ajr.177.3.1770627

14. de Miguel Criado J, del Salto LG, Rivas PF, del Hoyo LF, Velasco LG, de las Vacas MI, et al. MR imaging evaluation of perianal fistulas: Spectrum of imaging features. Radiographics. 2012;32(1):175-194. https://doi.org/10.1148/rg.321115040

15. Sainio P. Fistula-in-ano in a defined population. Incidence and epidemiological aspects. Ann Chir Gynaecol. 1984;73(4):219-224.

16. Gosselink MP, van Onkelen RS and Schouten WR. The cryptoglandular theory revisited. Colorectal Dis. 2015;17(12):1041-1043. https://doi.org/10.1111/codi.13161

17. Chaudhari $\mathrm{NH}$, Sinkar $A D$ and Samparna S. Role of magnetic resonance imaging in evaluation of perianal fistulas. Int J Res Med Sci. 2016;4:482-485. 
https://doi.org/10.18203/2320-6012.jijms20160300

18. Madireddy V, Gogi S, Ashwini J and Kumari VM. Efficacy of $\mathrm{MRI}$ in the diagnosis and grading of perianal fistula with surgical staging and correlation-a cross sectional study in a tertiary hospital. J Evid Based Med Healthc. 2020;9(41):2351-2355.

https://doi.org/10.18410/jebmh/2020/487

19. Daabis N, El Shafey R, Zakaria Y and Elkhadrawy O. Magnetic resonance imaging evaluation of perianal fistula. Egypt $\mathrm{J}$ Radiol Nucl Med. 2013;44(4):705-711.

https://doi.org/10.1016/j.ejrnm.2013.09.003

20. Singh K, Singh N, Thukral C, Singh KP and Bhalla V. Magnetic resonance imaging (MRI) evaluation of perianal fistulae with surgical correlation. J Clin Diagn Res. 2014;8(6):RC01-RC014. https://doi.org/10.7860/jcdr/2014/7328.4417

\section{Authors Contribution:}

SSK, DBD- Concept and design of the study; interpreted the results, prepared first draft of manuscript and critical revision of the manuscript; SGP- Statistically analyzed and interpreted; reviewed the literature and manuscript preparation; VD- Design of the study, statistically analyzed and interpreted, preparation of manuscript and revision of the manuscript; SP, TAP-Concept and coordination of the overall study.

\section{Work attributed to:}

MGM Medical College and Hospital, Aurangabad, Maharashtra, India.

Orcid ID:

Saurabh S Kakani - (10 https://orcid.org/0000-0001-5978-8726

Devidas B Dahiphale - (1) https://orcid.org/0000-0003-2400-1983

Saurabh G Padiya - (D) https://orcid.org/0000-0001-7939-7730

Vimal Dugad - (iD https://orcid.org/0000-0001-9990-9705

Shivaji M Pole - (1) https://orcid.org/0000-0002-2535-2403

Tanushree A Poddar - (i) https://orcid.org/0000-0002-7177-1297

Source of Funding: None, Conflicts of Interest: None. 